\title{
The influence of CSN3 and LGB polymorphisms on milk production and chemical composition in Romanian Simmental cattle
}

\author{
Radu Ionel Neamt ${ }^{\llbracket}$, Silviu Saplacan1, Stelian Acatincai², Ludovic Toma Cziszter ${ }^{1,2}$, Dinu \\ Gavojdian ${ }^{1}$ and Daniela Elena Ilie ${ }^{1}$
}

1Research and Development Station for Bovine - Arad, Arad, 310059, Romania; ${ }^{2}$ Banat's University of Agricultural Sciences and Veterinary Medicine "King Michael I of Romania" from Timisoara, Timisoara, 300645, Romania

The aim of this study was to assess the influence of genotypes from the CSN3 and LGB loci on milk production and chemical composition in Romanian Simmental cattle $(n=114)$. For the CSN3 locus a significantly higher frequency $(P \leq 0.001)$ was observed for the allele $A(0.785)$ compared to allele $B(0.215)$ and for $A A(0.631)$ compared to $A B(0.307)$ and $B B(0.062)$ genotypes, respectively. The $A A$ genotype was associated with a higher milk production $(5887.76 \pm 115.7 \mathrm{~kg})$ compared to the yields associated with the $B B$ genotype $(5619 \pm 86.34 \mathrm{~kg}$, $P \leq 0.003)$, as well as a higher fat percentage $(4.19 \pm 0.05 \%$ vs. $4.01 \pm 0.02 \%, P \leq 0.001)$. A higher milk protein percentage was associated with $B B(3.4 \pm 0.02 \%)$ compared to $A A(3.27 \pm 0.03)$ and $A B(3.29 \pm 0.03)$ genotypes, respectively $(P \leq 0.05)$. For the $L G B$ locus, the frequency of allele $A$ was significantly higher $(0.606, P \leq 0.008)$ than allele $B$ (0.394). The $A B$ genotype was the most prevalent in the herd (0.579) compared to $A A(0.316)$ and $B B$ genotypes (0.105). The $A B$ genotype was associated with a higher milk production $(5906.54 \pm 166.76 \mathrm{~kg})$ compared with the other two genotypes $(P \leq 0.05)$. The $B B$ genotype was associated with a higher fat percentage in milk $(4.23 \pm 0.06 \%)$ compared with $A A(4.17 \pm 0.06)$ and $A B(4.2 \pm 0.08)$ genotypes, respectively $(P \leq 0.01)$. For the $L G B$ locus, no significant differences $(P>0.05)$ were observed for milk protein percentage. In order to increase the quantity and quality of milk, the outcomes obtained in this study encourage improving genetic structure in cattle based on marker assisted selection for genes with economic values.

Key words: k-casein; $\beta$-lactoglobulin; Romanian Simmental cattle breed; milk production traits

Received: 16 November, 2016; revised: 10 July, 2017; accepted: 10 July, 2017; available on-line: 30 August, 2017

e-mail: neamtr@yahoo.com

Abbreviations: ANOVA, analysis of variance; $B R$, Romanian Simmental; CSN3, K-casein; DNA, deoxyribonucleic acid; LGB, $\beta$-lactoglobulin; LSM, least squares mean; MAS, marker assisted selection; PCR-RFLP, polymerase chain reaction-restriction fragment length polymorphism; SEM, standard error of mean

\section{INTRODUCTION}

The Romanian cattle population is quite high. There are 2092000 cattle in Romania according to the National Institute of Statistics (I.N.S., 2015). Thereby, Romania is among the top ten countries in the EU regarding the cattle population. From the total breed structure, a third of the population is represented by the Romanian Simmental
(Bălțată românească - BR) breed (30.96\%), according to the National Agency for Animal Improving and Reproduction from Romania. The Romanian Simmental breed is preferred by farmers due to high organic resistance, high longevity (8-10 lactations) and an excellent adaptive capacity to the environment and rearing systems. Being a dual purpose breed, the genetic improvement schemes are focused on milk production $(60 \%)$, meat $(35 \%)$ and fitness (5\%). An Official Performance Recording Scheme reports an average milk production level of 5000 to 5500 $\mathrm{kg} /$ lactation. Chemical composition of milk is characterized by an average percentage of 3.5 to $4.3 \%$ fat and 3.3 to $3.5 \%$ protein (Acatincai \& Cziszter, 2010). The Romanian Simmental breed is suitable for extensive, semi-intensive and even intensive rearing systems having good aptitudes for mechanical milking $(1.9-2.2 \mathrm{~kg} / \mathrm{min})$. The growing interest of the dairy industry for high biological value products motivates this study, requesting a good knowledge related to genetic polymorphism, milk's chemical composition and processing properties. The dominance of the BR breed and milk obtained from that cattle, among other breeds reared in Romania, requires a good knowledge of the genetic structure and polymorphism of genes with an economical importance. Furthermore, improving the breed's genetic structure is necessary to improve the overall quality of milk and related products.

Increasing a given farm's efficiency through rapid genetic gain is a current goal imposed by the competitive milk market on one hand, and an increased consumer demand for products with high biological value on the other hand. The major selection traits for improving cattle during the last 70 years were milk production and lactation length. However, during the last decades, genetic polymorphism studies of milk protein genes attracted the interest of the dairy industry and the marker assisted selection (MAS) started to be more and more frequently included in the selection programs. Researchers have identified different genetic markers in cattle that contribute to both, achieving a higher milk production and a better milk quality. In dairy cattle, studies have been focused on the most important economic traits: milk yield, fat and protein content, somatic cells count, fertility, longevity, health traits, temperament and conformation. The recent MAS studies regarding the quantity and quality of milk were focused on the genotypes of the CSN3 and LGB loci, encoding $x$-casein and $\beta$-lactoglobulin proteins which play an important role in determining the milk's biological value (Singh et al., 2015).

Knowledge of the genetic structure of cattle allows implementation of modern and fast methods in the genetic improvement programs that will lead to an increase 
in the dairy farms' efficiency. Furthermore, by using parental favourable genotypes for future breeding, farmers might create the premises to obtain milk with high biological value, according to the current needs of the market. Most of the studies have focused on favourable genotypes and alleles for milk yields in the dairy breeds. Worldwide, outcomes obtained regarding the correlations between the CSN3 and LGB genotypes and milk performances are contradictory. Currently, there is a lack of knowledge for dual purpose breeds, particularly in Romanian Simmental, about the CSN3 and LGB genetic variants (Ilie et al., 2009; Balteanu et al., 2010; Gradinaru et al., 2013, 2015), and there are very few outcomes regarding correlations between genetic polymorphism, milk yield, chemical composition and processing properties (Ilie et al., 2009; Gradinaru et al., 2013). Therefore, the importance of indigenous breeds as gene reservoirs is recognized worldwide and requests more precise outcomes (Kusza, et al., 2015). The results found on individual genotypes bring important insights that can be used in the future breeding and marker assisted selection programs for the Simmental cattle breed group.

The aim of the research presented here was to determine the genotypes and allele frequency of the CSN3 and LGB loci, and to correlate these results with the milk yield and milk chemical composition in the Romanian Simmental dual purpose cattle breed.

\section{MATERIALS AND METHODS}

General description. This study was carried out at the Research and Development Station for Bovine Arad-

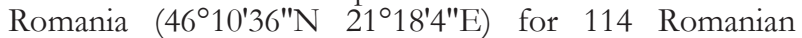
Simmental (national name: Bălțată românească; other English names: Romanian Spotted or Romanian Fleckvieh) dual purpose cows reared year around under the loose system, with no access to grazing. Cows included in the study were randomly selected, being between their 1 st and 6th lactation (1st, $\mathrm{n}=22 ; 2 \mathrm{nd}, \mathrm{n}=28 ; 3 \mathrm{rd}$, $\mathrm{n}=14,4$ th, $\mathrm{n}=19 ; 5$ th, $\mathrm{n}=16$; 6th, $\mathrm{n}=15)$. All cows were included in the Official Performance Recording Scheme through which the milk production and chemical composition data were registered. Cows were milked twice per day in a 'herringbone' milking parlour ( 2 sides $\times 14$ units). The milking parlour was equipped with AfiMilk 3.076 A-DU ${ }^{\circledR}$ software.

The research activities were performed in accordance with the European Union's Directive for animal experimentation (Directive 2010/63/EU). All procedures performed on cows in this study were approved by the Scientific Committee of the Research and Development Station for Bovine Arad.

Genetic analysis. Blood samples used for DNA genotyping were collected from the tail vein (vena cava) into $2 \mathrm{~mL}$ vacuum tubes containing the anticoagulant $\mathrm{K}_{3}$ EDTA. Genomic DNA was extracted from blood samples using two types of kits: a manual kit- Wizard Genomic DNA Purification Kit (Promega, Madison, USA), and an automated kit - InnuPREP Blood DNA Mini Kit - IPC 16 (Analytikjena, Berlin, Germany) using an automatic extractor InnuPure C16, according to the manufacturers' instructions. After extraction, the DNA concentration was spectrophotometrically evaluated with NanoDrop-2000 (Thermo Fisher Scientific, MA, USA). For the genotyping of animals, the Polymerase Chain Reaction and Restriction Fragment Length Polymorphism (PCR-RFLP) technique was used (Medrano \& Cordova, 1990 a,b). The geno- types for CSN3 were identified based on the amplification of a $350 \mathrm{bp}$ fragment, using the forward primer 5'-ATC ATT TAT GGC CAT TCC ACC AAA G-3' and the reverse primer 3'-GCC CAT TTC GCC TTC TCT GTA ACA GA-5'. For the identification of the $A$ and $B$ alleles of $L G B$, a 247 bp fragment was amplified, using the forward primer 5'-TGT GCT GGA CAC CGA CTA CAA AAA G-3' and the reverse primer 5'GCT CCC GGT ATA TGA CCA CCC TCT-3'.

The PCR amplification was performed in a $25 \mu \mathrm{l}$ reaction containing: $1 \mu \mathrm{l}$ (50-100ng) of genomic DNA as template, 20 pmol concentration of forward and reverse primer, and $2 \times$ Go TaqGreen Master Mix (Promega, Madison, WI, USA) for the CSN3 amplification, and $2 \times$ DreamTaq Green Master Mix (Fermentas, Thermo Fisher Scientific, MA, USA) for the LGB amplification. Amplification was carried out with the C1000 Thermal Cycler PCR System (Biorad, California, USA) in 48-well PCR plates. PCR conditions for CSN3 were as follows: 5 min at $95^{\circ} \mathrm{C}, 35$ cycles of $30 \mathrm{sec}$ at $95^{\circ} \mathrm{C}, 30 \mathrm{sec}$ at $60^{\circ} \mathrm{C}$ and $30 \mathrm{sec}$ at $72^{\circ} \mathrm{C}$ and a final extension cycle of $7 \mathrm{~min}$ at $72^{\circ} \mathrm{C}$. For $L G B$, the reaction was subjected to $5 \mathrm{~min}$ at $95^{\circ} \mathrm{C}, 35$ cycles of $30 \mathrm{sec}$ at $95^{\circ} \mathrm{C}, 30 \mathrm{sec}$ at $63^{\circ} \mathrm{C}$ and $30 \mathrm{sec}$ at $72^{\circ} \mathrm{C}$ and a final extension cycle of $7 \mathrm{~min}$ at $72^{\circ} \mathrm{C}$. Genotype detection was performed using the RFLP technique. The obtained PCR amplicons were digested for three hours at $37^{\circ} \mathrm{C}$ with the HindIII restriction enzyme for CSN3, and with HaeIII endonuclease for LGB. The PCR-RFLP fragments for CSN3 and LGB were separated on 3.5\% agarose gels.

Data recording and statistical analysis. Production data collection. Milk yield and chemical composition (total fat yield and percentage, total protein yield and percentage) were recorded by the Official Performance Recording Scheme technicians. The alternative milking $\mathrm{AM} / \mathrm{PM}$ at a 28 day interval protocol was used for this purpose. Milk yield was standardized for mature equivalent (cow's parity) using correction coefficients (Acatincai \& Cziszter, 2010).

Statistical analysis. Production and milk quality data were analyzed statistically, being expressed as LSM \pm S.E.M. Comparisons between the three genotypes for production level and quality of milk were carried out using a one-way ANOVA protocol with the genotype of cows considered as the categorical factor. Differences between the three genotypes were statistically tested using the Shapiro-Wilks test (Shapiro \& Wilk, 1965). Decisions about the acceptance or rejection of the statistical hypothesis have been made at the 0.05 level of significance. All the statistical inferences were carried out using Statistica software v.13.0 (Hill \& Lewicki, 2007).

\section{RESULTS AND DISCUSSION}

In the study presented here, the CSN3 and LGB loci have been genotyped using the PCR-RFLP method. For both loci, three genotypes $(A A, A B, B B)$ and two alleles $(A, B)$ have been identified. The alleles and the genotype frequency for the CSN3 and LGB loci of the Romanian Simmental breed are presented in Table 1.

\section{Alleles and the genotype frequency for the CSN3 locus}

Within the studied herd, a significantly higher frequency of allele $A(0.785)$ compared with the allele $B(0.215)$ for the CSN3 locus was recorded. The $A A$ genotype prevailed in the studied herd (0.631) compared to $A B(0.307)$ and $B B$ genotypes (0.062), respectively. Similar results were obtained in the few studies conducted for the local 
Table 1. Polymorphism of the CSN3 and LGB loci for the studied Romanian Simmental cow herd

\begin{tabular}{llll}
\hline Locus & Genotype & Frequency & Allele (frequency) \\
\hline & $A A$ & $0.631^{a}$ & \\
CSN3 & AB & $0.307^{b}$ & $\mathrm{p}_{\mathrm{A}}-0.785^{\mathrm{a}}$ \\
& $\mathrm{BB}$ & $0.062^{c}$ & $\mathrm{q}_{\mathrm{B}}-0.215^{\mathrm{b}}$ \\
& $\mathrm{AA}$ & $0.316^{\mathrm{a}}$ & \\
\hline \multirow{4}{*}{ LGB } & $\mathrm{AB}$ & $0.579^{\mathrm{b}}$ & $\mathrm{p}_{\mathrm{A}}-0.606^{\mathrm{a}}$ \\
& $\mathrm{BB}$ & $0.105^{c}$ & $\mathrm{q}_{\mathrm{B}}-0.394^{\mathrm{b}}$ \\
\hline
\end{tabular}

Different superscript per column $(\mathrm{a}, \mathrm{b}, \mathrm{c})$ differ significantly at $P \leq 0.05$, within the same locus

cattle breeds in Romania (Romanian Simmental) where an increased frequencies of allele $A$ (from 0.679 up to 0.761 ) compared to $B$ (from 0.239 up to 0.313 ) was recorded (Balteanu et al., 2010; Gradinaru et al., 2013, 2015). The frequencies of genotypes reached 0.461, 0.427, and 0.097 for $A A, A B$ and $B B$, respectively (Balteanu et al., 2010). For the Romanian local Brown breed, in successive studies conducted by Ilie et al. (2008, 2015), an increased frequency of the $B$ allele (0.625 to 0.63 ) compared with the $A$ allele (0.37) in the CSN3 locus highlighted, although the frequency of the $B B$ genotype was recorded to have a lower value (0.3 to 0.33 ) when compared to the $A B$ genotype ( 0.63 to 0.58$)$. The Romanian milk production specialized breed (Romanian Black and White, HolsteinFriesian type) had an increased frequencies of the $A$ allele (0.761), as well as $A A(0.609)$ and $A B(0.304)$ genotypes when compared to the values obtained for the $B$ allele (0.239) and $B B$ homozygous genotype $(0.087)$ in the CSN3 locus (Ilie et al., 2008, 2015). A recent study conducted by Bartonovaand coworkers (2012) for the Czech Fleckvieh breed, revealed a lower frequency of the $A A$ genotype (0.296) and an increased share of the $A B(0.487)$ and $B B(0.158)$ genotypes, respectively. Bonfatti and coworkers (2010) found higher frequencies of the AA (0.438) and $\mathrm{AB}(0.432)$ compared to the $\mathrm{BB}(0.13)$ genotypes, in a study conducted on Simmental cows. An unbalanced distribution was recorded for the allele's frequencies, 0.652 for allele $A$ and 0.348 for allele $B$.

Higher frequency of allele $B$ was found within genetically unimproved breeds (0.3) when compared to a reduced frequency of this allele $(0.01-0.2)$ found in their hybrids with milk production specialized breeds (Holstein Friesian) (Azevedo et al., 2008).Variable frequencies of allele $B(0.16-0.5)$ and homozygous $B B$ genotype (0.02-0.25) were found in local breeds from the Russian
Federation (Sulimova et al., 2007). Several studies reported a low frequency of allele $B$ in specialized breeds for milk production. Specific variations were also calculated by Strzalkowska and coworkers (2002) for dairy breeds (Polish Black and White). Low frequency was recorded for homozygous $B B$ genotype (0.04) when compared to the $A A$ (90.57) and $A B$ genotypes (9.39), respectively. The frequency of allele $A$ was significantly higher (0.77) compared with the frequency of allele $B(0.23)$ for the CSN3 locus (Strzalkowska et al., 2002). Significant variations in the frequency of alleles $A$ and $B$ and default for the three genotypes related to the CSN3 locus were calculated by Tsiaras and coworkers (2005). Studies conducted for the Holstein Friesian cows had revealed a frequency of 0.81 for the homozygous $A A$ genotype, 0.14 for the heterozygous $A B$ genotype and 0.05 for the homozygous $B B$ genotype. The results obtained by Sitkowska (2008) for the Holstein Friesian cows confirm the earlier outcomes. For the herd included in the evaluation, frequencies of 0.71 for the $A A$ genotype, 0.23 to 0.06 for the $A B$ and $B B$ genotypes, respectively, were calculated in the CSN3 locus. The frequency of allele $A$ was higher (0.83) when compared to that of allele $B(0.17)$ (Sitkowska et al., 2008). Similar outcomes were found by Lara et al. (2002). Conversely, Bencsik and coworkers (2007) recorded an increased frequency of the homozygous $B B$ genotype (0.33), as well as 0.5 for $A B$, and 0.17 for $A A$ genotypes, in the CSN3 locus for a Holstein Friesian herd. The frequency of allele $A$ was 0.43 in comparison to 0.57 for allele $B$ (Bencsik et al., 2007).

\section{Alleles and the genotype frequency in the LGB locus}

Unbalanced distribution was recorded for genotype frequency in the $L G B$ locus. Higher frequency was found for the heterozygous $A B$ genotype (0.579) compared with $A A(0.316)$ and $B B(0.105)$, respectively. Much closer values were recorded for the two allele frequencies in the LGB locus, 0.606 for $A$ when compared to 0.394 for the $B$ allele $(P \leq 0.008$, Table 1$)$. A comparative study conducted by Gradinaru et al. (2013) for the Romanian Simmental cows, had found similar values for these two alleles, 0.525 for $A$ and 0.451 for the $B$ allele, respectively. Low frequency of allele $A$ was recorded in the same study for the Montbeliarde breed (0.306) when compared to a high frequency of allele $B(0.694)$. Comparable results were provided by Balteanu and coworkers (2010) in a study conducted for the Romanian Simmental cattle that recorded a frequency of 0.515 for allele $A$ and 0.481 for allele $B$. Similar outcomes were provided by Bonfatti and coworkers (2010) and highlighted closer values for alleles $A$ and $\mathrm{B}$ in the Simmental cows (0.543 and 0.449 , respectively).

Table 2. Least square means ( \pm S.E.M.) for milk production and chemical composition according to the CSN3 and LGB loci in the Romanian Simmental dual purpose breed

\begin{tabular}{|c|c|c|c|c|c|}
\hline Variation source & $\begin{array}{l}\text { Milk } \\
(\mathrm{kg})\end{array}$ & $\begin{array}{l}\text { Fat } \\
(\%)\end{array}$ & $\begin{array}{l}\text { Fat } \\
(\mathrm{kg})\end{array}$ & $\begin{array}{l}\text { Protein } \\
(\%)\end{array}$ & $\begin{array}{l}\text { Protein } \\
(\mathrm{kg})\end{array}$ \\
\hline \multicolumn{6}{|l|}{ CSN3 } \\
\hline AA & $5887.76 \pm 115.7 a$ & $4.19 \pm 0.05^{a}$ & $246.68 \pm 6.83^{a}$ & $3.27 \pm 0.03^{a}$ & $192.52 \pm 4.12^{a}$ \\
\hline$A B$ & $5839.37 \pm 117.8^{a}$ & $4.08 \pm 0.06^{b}$ & $238.24 \pm 9.1^{a}$ & $3.29 \pm 0.03^{a}$ & $192.11 \pm 6.6^{a}$ \\
\hline $\mathrm{BB}$ & $5619 \pm 86.34^{b}$ & $4.01 \pm 0.02^{b}$ & $225.32 \pm 4.69^{b}$ & $3.4 \pm 0.02^{b}$ & $191.04 \pm 3.61^{\mathrm{a}}$ \\
\hline \multicolumn{6}{|l|}{ LGB } \\
\hline AA & $5809 \pm 117.58^{a}$ & $4.17 \pm 0.06^{a}$ & $242.23 \pm 9.96^{a}$ & $3.31 \pm 0.04^{a}$ & $192.27 \pm 5.43^{a}$ \\
\hline$A B$ & $5906.54 \pm 166.76^{b}$ & $4.2 \pm 0.08^{b}$ & $248.07 \pm 5.93^{a}$ & $3.34 \pm 0.05^{a}$ & $197.27 \pm 6.19^{b}$ \\
\hline BB & $5812 \pm 115.11^{a}$ & $4.23 \pm 0.06^{c}$ & $245.84 \pm 7.71^{\mathrm{a}}$ & $3.33 \pm 0.01^{a}$ & $193.53 \pm 3.94^{a}$ \\
\hline
\end{tabular}

Columns means with different superscript $(a, b, c)$ differ significantly at $P \leq 0.05$, within the same variation source 
For a Romanian local Brown breed, studies conducted by Ilie and coworkers (2009), reported a fairly close frequency for the homozygous genotypes, 0.13 for $A A$ and 0.17 for $B B$ genotype, respectively. In a study conducted by Bonfatti and coworkers (2010) for the Simmental cows, a similar distribution of the genotype frequency was reported, providing a higher share of the $A B$ genotype (0.466) compared to the $A A(0.306)$ and $B B(0.213)$ genotypes. In other works on dairy breeds, it was found that the frequency of allele $A$ was 0.57 and for allele $B$ was 0.43 . The genotype frequency was 0.43 for $A A, 0.29$ for $B B$ and 0.28 for $A B$ (Yahya et al., 2013).

The effects of the CSN3 and LGB loci on milk production and chemical composition are presented in $\mathrm{Ta}-$ ble 2 .

\section{The CSN3 genotype's influence on milk production and chemical composition}

The highest milk production was recorded for the $A A$ genotype in the CSN3 locus (5887.76 $1115.7 \mathrm{~kg})$. This production was significantly higher $(P \leq 0.003)$ than that observed for the $B B$ genotype $(5619 \pm 86.34 \mathrm{~kg})$. No significant differences $(P>0.37)$ were recorded between the $A A$ and $A B(5839.37 \pm 117.8 \mathrm{~kg})$ genotypes. Milk production associated with the $A B$ genotype proved to be significantly higher $(P \leq 0.007)$ when compared to that associated with the $B B$ genotype $(5619 \pm 86.34 \mathrm{~kg})$. These results confirm previous studies conducted by Lara and coworkers osite outcomes, with a higher production of milk being associated with the $B B$ genotype. No significant differences were obtained between $A A$ and $B B$ genotypes in other studies conducted by Strzalkowska and coworkers (2002) for Holstein Friesians and Felenczak and coworkers (2008) for the Simmentals-Research conducted by Gradinaru and coworkers (2013) for the Romanian Simmental cattle, recorded a higher milk production associated with the $B B$, while the lowest production level was associated to the $A A$ genotype. Bugeac and coworkers (2013) found an increase in milk production associated with the $A B$ genotype in a study conducted for the Montbeliarde breed.

The $A A$ genotype favoured a higher fat percentage in milk $(4.19 \pm 0.05 \%)$ compared to the $A B$ genotype $(4.08 \pm 0.06 \%, P \leq 0.04)$ and $B B$ genotype (4.01 $\pm 0.02 \%$, $P \leq 0.008)$. These outcomes were consistent with previous results found by Tsiaras and coworkers (2005), Bencsik and coworkers (2007) and Sitkowska and coworkers (2008). In a study conducted for the Simmental cows, Felenczak and coworkers (2008), found opposite outcomes, the higher milk fat content being associated with the $B B$ genotype $(4.12 \pm 0.3 \%)$ when compared to $A A$ $(4.04 \pm 0.29 \%)$ and $A B(4.08 \pm 0.32 \%)$ genotypes. Gradinaru and coworkers (2013) obtained similar values for the milk fat content between the three genotypes; however, there was a tendency for cows with the $B B$ genotype to have a higher fat content in milk. This influenced the total fat yield, reaching a value of $246.68 \pm 6.83 \mathrm{~kg}$ associated with the $A A$ genotype, and a comparable value associated with the $A B$ genotype (238.24 $\pm 9.1 \mathrm{~kg}, P>0.63)$, but significantly higher when compared to the $B B$ genotype (225.32 $\pm 4.69 \mathrm{~kg}, P \leq 0.018)$.

When assessed for the $\mathrm{AA}$ and $\mathrm{AB}$ genotypes, the percentage of milk protein had significantly lower values compared to the $\mathrm{BB}$ genotype $(3.27 \pm 0.03 \%, P \leq 0.012$, $3.29 \pm 0.03 \%, P \leq 0.036,3.4 \pm 0.02 \%$, respectively). These results were in accordance with previous outcomes obtained by Lara and coworkers (2002), Strzalkowska and coworkers (2002) and Bencsik and coworkers (2007) but in contradiction with those obtained by Tsiaras and coworkers (2005) and Sitkowska and coworkers (2008) for dairy breeds. Felenczak and coworkers (2008) found that a higher value for milk fat content is associated with the BB genotype in a study conducted with Simmental cattle, $3.53 \pm 0.18 \%$ for $B B$ when compared to $3.46 \pm 0.19 \%$ for the $A A$ genotype. Scientific literature provides some outcomes that highlight no significant influence of genotype on milk protein content for the Romanian Simmental breed (Gradinaru et al., 2013). In our study, the total protein yield was not influences by the CSN3 genotype, Average values for milk protein yield were 192.52 \pm 4.12 $\mathrm{kg}$ for the $A A, 192.11 \pm 6.6 \mathrm{~kg}$ for $A B, 191.04 \pm 3.61 \mathrm{~kg}$ for the $B B$ genotype, respectively. These outcomes were consistent with results previously found by Gradinaru and coworkers (2013) and Felenczak and coworkers (2008).

\section{The LGB genotype's influence on milk production and chemical composition}

The productive traits were assessed according to the three genotypes in the $L G B$ locus. The highest milk production was recorded for the $A B$ genotype $(5906.54 \pm 166.76 \mathrm{~kg})$, being significantly different from that produced by the $A A(5809 \pm 117.58 \mathrm{~kg}, P \leq 0.033)$ and $B B$ genotypes $(5812 \pm 115.11 \mathrm{~kg}, P \leq 0.038)$. This result was inconsistent with previous findings of Ilie and coworkers (2009) for the Romanian Brown breed, and Strzalkowska and coworkers (2002) and Tsiaras and coworkers (2005) for dairy breeds. Conflicting outcomes were found by Ojala and coworkers (1997) whose studies recorded no significant association between genotypes and milk production. Some studies found a positive association between the BB genotype and milk yield (Yahya et al., 2013). For the Romanian Simmental breed, the results provided by Gradinaru and coworkers (2013) did not recorded a significant influence of LGB genotypes on milk production level, 6289.9 $\pm 134.1,6540.1 \pm 97.1,6537.8 \pm 149.9 \mathrm{~kg} /$ lactation for $A A, A B$ and $B B$, respectively.

A significantly higher fat percentage was recorded for the $B B$ genotype $(4.23 \pm 0.06 \%)$ when compared to the $A A$ $(4.17 \pm 0.06 \%, P \leq 0.003)$ and $A B$ genotypes (4.2 $\pm 0.08 \%$, $P \leq 0.011$ ), as previously reported by Ahmadi and coworkers (2008) for the Holstein cows. Gradinaru and coworkers (2013) in a study conducted for the Romanian Spotted breed had found a similar fat content for the $A A, A B$ and $B B$ genotypes. In our study, there were no significant differences in the fat yield between the three genotypes: $A B(248.07 \pm 5.93 \mathrm{~kg}), A A(242.23 \pm 9.96 \mathrm{~kg}, P>0.42)$ and $B B(245.84 \pm 7.71 \mathrm{~kg}, P>0.31)$. Similar results were reported by Gradinaru and coworkers (2013).

An average protein percentage in milk of $3.34 \pm 0.05 \%$ was associated with the $A B$ genotype, while a value of $3.31 \pm 0.04 \% \quad(P>0.57)$ was associated with the $A A$ and $3.33 \pm 0.01 \%(P>0.081)$ with the $B B$ genotype. This highlights that the $L G B$ genotype has no significant influence on the protein content of milk. These results are similar to previous findings by Gradinaru and coworkers (2013) obtained for the Romanian Simmental cows and are conflicting with results obtained by Ahmadi and coworkers (2008). In our study, the total milk protein yield was significantly lower in $A A(192.27 \pm 5.43 \mathrm{~kg}, P \leq 0.042)$ and $B B$ $(193.53 \pm 3.94 \mathrm{~kg}, P \leq 0.026)$ homozygous genotypes when compared to the $A B$ heterozygous genotype (197.27 \pm 6.19 $\mathrm{kg})$. No significant differences $(P>0.34)$ were recorded between the $A A(192.27 \pm 5.43 \mathrm{~kg})$ and $B B(193.53 \pm 3.94 \mathrm{~kg})$ homozygous genotypes, for the total milk protein yield.

In some previous studies regarding frequencies of alleles and genotypes in CSN3 and LGB different results were re- 
corded probably due to genetic improvement schemes applied into herds. Moreover, along the same breed, the results obtained by different authors are inconsistent due to many potentially influential factors, such as the rearing areas and rearing conditions, weather conditions, nutritional support, age of cows, animal's welfare state, accuracy of data recording, data analysis methods etc. Due to these inconsistent results, more studies regarding these issues are necessary, particularly for the local dual-purpose breeds.

\section{CONCLUSIONS}

The current study offers preliminary results regarding the influence of CSN3 and LGB genotypes on the milk yield and milk chemical composition.

For the CSN3 locus, higher milk productions were associated with the $A A$ and $A B$ genotypes. The homozygous $B B$ genotype was negatively associated with the milk yield. The fat percentage was positively influenced by the $A A$ genotype, which was significantly higher when compared to the values associated with the $A B$ and $B B$ genotypes. The $A A$ and $A B$ genotypes were negatively associated with the protein percentage when compared to the $B B$ genotype.

For the $L G B$ locus, the $A B$ genotype was positively associated with the milk production. Significantly higher fat percentage for the $B B$ homozygous genotype was recorded. Milk protein percentage was negatively associated with the LGB genotype. No significant differences were recorded between the three genotypes.

The importance of study is that it proves the influence of individual genotypes on milk quality. The studies focusing on the frequency of alleles and genotypes in the CSN3 and LGB loci have offered various results according to the cows' breed. Nevertheless, more studies are necessary due to contradictory outcomes found within the literature. The future plan is to characterize a larger number of animals from different areas of the country, for milk proteins' genetic variants in order to contribute to a better knowledge of the breed genetic structure. Furthermore, individual genotypes could be used in the future for the marker assisted selection programs, and could be included in the future selection scheme of the breed.

\section{Acknowledgements}

This work was supported by a grant of the Romanian National Authority for Scientific Research and Innovation, CNCS - UEFISCDI, project number PN-II-RUTE-2014-4-1402 and by a grant of the Romanian Ministry of Agriculture and Rural Development, throughout the project ADER 5.1.5.

The authors would like to thank Radu Onut and Florin Marinescu for their assistance in blood sampling and production data collection.

\section{REFERENCES}

Acatincai S, Cziszter LT (2010) Animal productions. Agroprint ed., p 112-115. Timisoara (in Romanian)

Ahmadi M, Mohammadi Y, Darmani Kuhi H, Osfoori R, Qanbari S (2008) Association of milk protein genotypes with production traits and somatic cell count of Holstein Cows. J Biol Sci 8: 1231-1235. doi: $10.3923 /$ jbs.2008.1231.1235

Azevedo AL, Nascimento CS, Steinberg RS, Carvalho MR, Peixoto MG, Teodoro RL, Verneque RS, Guimaraes SE, Machado MA (2008) Genetic polymorphism of the kappa-casein gene in Brazilian cattle. Genet Mol Res 7: 623-630. doi: 10.4238/vol7-3gmr428

Balteanu AV, Vlaic A, Suteu M, Carsai T (2010) A comparative study of major milk protein polymorphism in six Romanian cattle breed. Bull UASVM Animal Scie Bio 67: 345-350
Bartonova P, Vrtkova I, Kaplanova K, Urban T (2012) Association between CSN3 and BCO2 gene polymorphisms and milk performance traits in the Czech Fleckvieh cattle breed. Gen Mol Res 11: 1058-1063. http://dx.doi.org/10.4238/2012.April.27.4

Bencsik I, Pacala N, Stanculet J, Telea A, Bencsik A (2007) The influence of k-casein alleles on milk production and quality in a Holstein-Frisian cow population. Sci Pap Anim Sci Biotech 40: 13-17

Bonfatti V, Di Martino G, Cecchinato A, Vicario D, Carnier P (2010) Effects of $\beta$ - $x$-casein (CSN2-CSN3) haplotypes and $\beta$-lactoglobulin (BLG) genotypes on milk production traits and detailed protein composition of individual milk of Simmental cows. J Dairy Sci 93: 3797-3808. doi: 1 0.3168/jds.2009-2778

Bugeac T, Balteanu VA, Creanga S (2013) Kappa-casein genetic variants and their relationships with milk production and quality in Montbéliarde dairy cows. Bull UASVM Animal Scie Bio 70: 193-194

Felenczak A, Gil Z, Adamczyk K, Zapletal P, Frelich J (2008) Polymorphism of milk $x$-casein with regard to milk yield and reproductive traits of Simmental cows. I Agrobiology 25: 201-207

Grădinaru AC, Ilie DE, Creangă S (2015) The effect of casein genotypes selection on the genetic structure of Romanian Spotted, Holstein Friesian and Montbéliarde cattle populations and the genetic variability of kappa-casein and beta-lactoglobulin in Romanian Grey Steppe. Res J Biotech 10: 91-98

Grădinaru AC, Ilie DE, Creangă S (2013) Milk protein genetic variants in Romanian Spotted, Holstein Friesian and Montbéliarde cows and some correlations with milk parameters. Res J Biotech 8: 3-9

Hill T, Lewicki P (2007) Statistics: Methods and Applications. StatSoft, Tulsa, OK, USA

Ilie DE, Magdin A, Salajeanu A, Neamt RI, Vintila I (2008) Analysis of genetic polymorphism at the CSN3 and BLG locus in some dairy breeds from west part of country. Scientific reports of ICDCB Balotesti, Ceres Ed, p 40-45, Romania

Ilie DE, Magdin A, Salajeanu A, Neamt RI, Vintila I (2009) Influence of CSN 3 marker on milk composition in Romanian Brown and Romanian Simmental cattle from SCDCB Arad. Sci Pap Anim Sci Biotech 42: 54-57

Ilie DE, Neamt RI (2015) Effects of sires genotyping for $x$-casein on $\mathrm{B}$ allele frequency in Romanian Brown cattle. In International scientific symposium, Bioengineering of animal resources, p 204, Timisoara, Romania

I.N.S. (2015) Annual Report of Romanian National Institute of Statistic - Bovine herds existing on 1st June 2014, No. 228 / 22 September 2014. Available from: http://www.insse.ro/cms/files/statistici/ comunicate/com_anuale/Efec_anim/ef.animale_r2014.pdf

Kusza S, Sziszkosz N, Nagy K, Masala A, Kukovics S, Andras J (2015) Preliminary result of a genetic polymorphism of $\beta$-lactoglobulin gene and the phylogenetic study of ten balkan and central european indigenous sheep breeds. Acta Biochim Pol 62: 109-112. doi: 10.18388/abp.2014_846

Lara MAC, Gama LT, Bufarah G, Sereno JRB, Celegato EML, Abreu UP (2002) Genetic polymorphisms at the $\mathrm{k}$-casein locus in Pantaneiro cattle. Arch Zootec 51: 99-105

Medrano JF, Cordova EA (1990a): Genotyping of bovine kappa-casein loci following DNA sequence amplification. Biotechnology 8: 144-146

Medrano JF, Cordova EA (1990b): Polymerase chain reaction amplification of bovine LGB genomic sequences and identification of genetic variants by RFLP analysis. Anim Biotech 1: 73-77

Ojala M, Famula TR, Medrano JF (1997) Effects of milk production genotypes on the variation of milk production traits of Holstein and Jersey cows in California. I Dairy Sci 80: 1776-1785

Shapiro SS, Wilk MB (1965) An analysis of variance test for normality (complete samples). Biometrika 52: 591-611

Singh LV, Jayakumar S, Sharma A, Gupta SK, Dixit SP, Gupta N, Gupta SC (2015) Comparative screening of single nucleotide polymorphism in $\beta$-casein and $\mathrm{k}$-casein gene in different breeds of India. Meta Gene 4: 85-91. doi: 10.1016/j.mgene.2015.03.005

Sitkowska B, Neja W, Wisniewska E (2008) Relations between kappacasein polymorphism (CSN3) and milk performance traits in heifer cows. J Cent Eur Agric 9: 641-644

Strzalkowska N, Josef K, Lech Z, Zofia R (2002) Effects of kappacasein and beta-bactoglobulin loci polymorphism, cows age, stage of lactation and somatic cell count on daily milk yield and milk composition in Polish Black and White cattle. Anim Sci Pap Rep 20: 21-35

Sulimova GE, Abani AM, Rostamzadeh I, Mohammad AMR, Lazebnyi OE (2007) Allelic polymorphism of kappa-casein gene (CSN-3) in Russian cattle breeds and its informative value as a genetic marker. Genetika 43: 88-95

Tsiaras AM, Bargouli GG, Banos G, Boscos CM (2005) Effect of kappa-casein and beta-lactoglobulin loci on milk production traits and reproductive performance of Holstein cows. J Dairy Sci 88: 327-334. doi: 10.3168/jds.S0022-0302(05)72692-8

Yahya M, Ali AA, Mohammad RN, Ali EK (2013) Allelic polymorphism of $x$-casein, $\beta$-lactoglobulin and leptin genes and their association with milk production traits in Iranian Holstein cattle. I Cell Mol Res 5: 75-80. doi: 10.14675/jcmr.v5i2.21086 